\title{
Editorial
}

\section{The 2011 Journal Citation Reports and the impact factor of the Journal of Applied Oral Science}

Dear Readers, Contributors and Reviewers,

On June $28^{\text {th }}$, Thomson Reuters released the 2011 Journal Citation Reports. As all of you could notice, the impact factor of the Journal of Applied Oral Science decreased from 0.966 to 0.575 as compared to the 2010 edition.

We were obviously frustrated and surprised with this outcome, but after a thorough analysis of the 81 journals in the Dentistry, Oral Surgery \& Medicine category, we observed that many other journals also had a decrease in their impact factors. In our case, the citations in 2011 were higher in comparison with 2010 (484 versus 404 citations, respectively), but since we published a higher number of articles the impact factor decreased as a direct consequence.

Nevertheless, we are glad that the third impact factor in 2011 (0.575) is at least higher than the first one in 2009 (0.386; when the journal had 201 citations). As we said in previous occasions, we believe that the increase in our impact factor will be a natural result throughout the years, and we will not adopt any specific procedure to change this scenario but keep our hard and serious work to publish good scientific works.

Thank you for all the support.

Yours sincerely,

\section{Carlos F. Santos}

Editor-in-Chief

Journal of Applied Oral Science 